\title{
Why complicate an important task? An orderly display of the limb leads in the 12-lead electrocardiogram and its implications for recognition of acute coronary syndrome
}

\author{
T. Lindow ${ }^{1,2,3^{*}}$ (D) Y. Birnbaum ${ }^{4}$, K. Nikus ${ }^{5,6}$, A. Maan ${ }^{7}$, U. Ekelund ${ }^{8}$ and O. Pahlm ${ }^{9}$
}

\begin{abstract}
Background: In the standard ECG display, limb leads are presented in a non-anatomical sequence: I, II, III, aVR, aVL, aVF. The Cabrera system is a display format which instead presents the limb leads in a cranial/left-to-caudal/right sequence, i.e. in an anatomically sequential order. Lead aVR is replaced in the Cabrera display by its inverted version, $-\mathrm{aVR}$, which is presented in its logical place between lead I and lead II.

Main text: In this debate article possible implications of using the Cabrera display, instead of the standard, noncontiguous lead display, are presented, focusing on its use in patients with possible acute coronary syndrome. The importance of appreciating reciprocal limb-lead ECG changes and the diagnostic and prognostic value of including aVR or lead -aVR in ECG interpretation in acute coronary syndrome is covered. Illustrative cases and ECGs are presented with both the standard and contiguous limb lead display for each ECG.

A contiguous lead display is useful when diagnosing acute coronary syndrome in at least 3 ways: 1) when contiguous leads are present adjacent to each other, identification of ST elevation in two contiguous leads is simple; 2) a contiguous lead display facilitates understanding of lead relationships as well as reciprocal changes; 3 ) it makes the common neglect of lead aVR unlikely.
\end{abstract}

Conlusions: It is logical to display the limb leads in their sequential anatomical order and it may have advantages both in diagnostics and ECG learning.

\section{Background}

ECG changes indicative of acute coronary occlusion or sub-occlusion serve as an important "watershed" in the early decision process in the management of patients with chest pain. ECG interpretation skills are therefore essential for any physician who encounters patients with suspected acute coronary syndrome. However, both accuracy and self-perceived confidence in ECG interpretation by internal-medicine and

\footnotetext{
* Correspondence: Thomas.a.lindow@gmail.com

'Department of Clinical Physiology, Växjö Central Hospital, Växjö, Sweden

${ }^{2}$ Department of Research and Development, Region Kronoberg, Sweden

Full list of author information is available at the end of the article
}

emergency-medicine residents have been reported to be low $[1,2]$.

In the standard 12-lead ECG, the precordial ECG leads are presented in an anatomical sequence, whereas the limb leads are most often presented as two groups of leads in a non-anatomical ("non-contiguous") order: I, II, III and aVR, aVL, aVF (Fig. 1). This order of limb-lead presentation has historical roots. Leads I, II and III were the first ECG leads introduced by Einthoven in the beginning of twentieth century, and the augmented limb leads (aVR, aVL, aVF) were introduced later (by Goldberger in the 1940's).

ECG waveforms in aVR are distinctly different from those in the other 5 leads, since it has its positive pole in the upper right quadrant of the thorax. Currents directed 


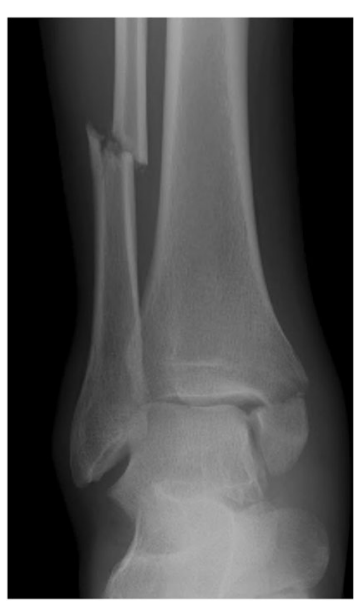

\section{"aVL"
"I"
"aVR"
"II"
"aVF"
"III"}

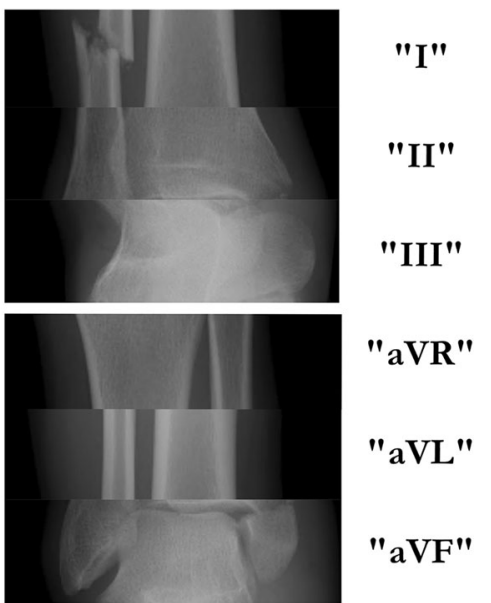

Fig. 1 A figurative description of the illogical presentation of limb leads in the ECG standard format by the use of an X-ray image of a bimalleolar ankle fracture. The radiological image is divided into six parts with lead annotations to the right of each image in order to illustrate both the orderly and non-orderly lead sequences. To the left, the image is presented with the skeletal parts and the lead annotations in their orderly anatomical sequence. The right image is presented in scrambled order representing the standard, non-orderly presentation of the frontal plane sequence of the 12-lead ECG

towards that positive pole will be represented as positive amplitudes in aVR, but as negative amplitudes in all other limb leads and vice versa. Thus, all reference values for $\mathrm{aVR}$ are completely different from those in the remaining leads. Q waves will become $R$ waves, and ST elevation will become ST depression, which makes both teaching/learning and interpretation unnecessarily difficult.

Since the amplitude in aVF at any point in time equals the average amplitude of leads II and III it would be logical to display it between these 2 leads. In that way, it is easier to understand the waveform progression between leads. Likewise, the amplitude at any time point in the inverse of aVR, denoted $-\mathrm{aVR}$, equals the average amplitude of leads I and II. Lead aVL equals the average amplitude of lead I and the inverse of lead III (-III). Hence, -aVR should logically be displayed between leads I and II, and aVL above lead I. Such a display is used in Sweden, the so-called Cabrera system, in which the limb leads are shown in a contiguous sequence at 30-degree intervals (Fig. 2) [3]. A contiguous lead display would be useful when diagnosing acute coronary syndrome in at least 3 ways: 1) when contiguous leads are presented adjacent to each other, identification of ST elevation in 2 contiguous leads is simple; 2) a contiguous lead display facilitates understanding of lead relationships; 3 ) it makes the common neglect of lead aVR unlikely. These aspects are explained and illustrated by ECG examples presented both with the standard, non-contiguous lead display and the contiguous display, the Cabrera sequence.

\section{Main text \\ The Cabrera display for diagnosing acute coronary syndrome}

The ECG is an essential diagnostic tool, since it is available very early in the management of patients with suspected acute coronary syndrome, often considerably earlier than biomarkers and other diagnostic modalities. The electrocardiographic diagnosis of ST-elevation myocardial infarction (STEMI) is based on presence of significant ST elevation in at least 2 anatomically contiguous leads [4]. In the standard presentation anatomically contiguous leads are not presented adjacently, which makes it unnecessarily difficult for the inexperienced ECG reader to apply the STEMI criteria. Only 3 lead pairs in the frontal plane can easily be recognized; aVL/I, II/aVF and III/ aVF. In the Cabrera format, 2 additional lead pairs are evident; I/-aVR and $-\mathrm{aVR} / \mathrm{II}$.

\section{Reciprocal changes}

Identification of reciprocal changes in the ECG is important when interpreting ECGs in patients with suspected acute myocardial infarction. To identify these changes, it is necessary to understand how the limb leads are related. In an orderly display of the limb leads, it is easier to appreciate which leads are anatomically adjacent to each other. Reciprocal changes within the frontal plane, i.e. among limb leads, are also important. Lead aVL is almost reciprocal to lead III, which means that ST elevation in III may coincide with ST depression in aVL. The latter could be described as $\mathrm{ST}$ elevation in $-\mathrm{aVL}$ (the inversion of lead $\mathrm{aVL}$ ). 


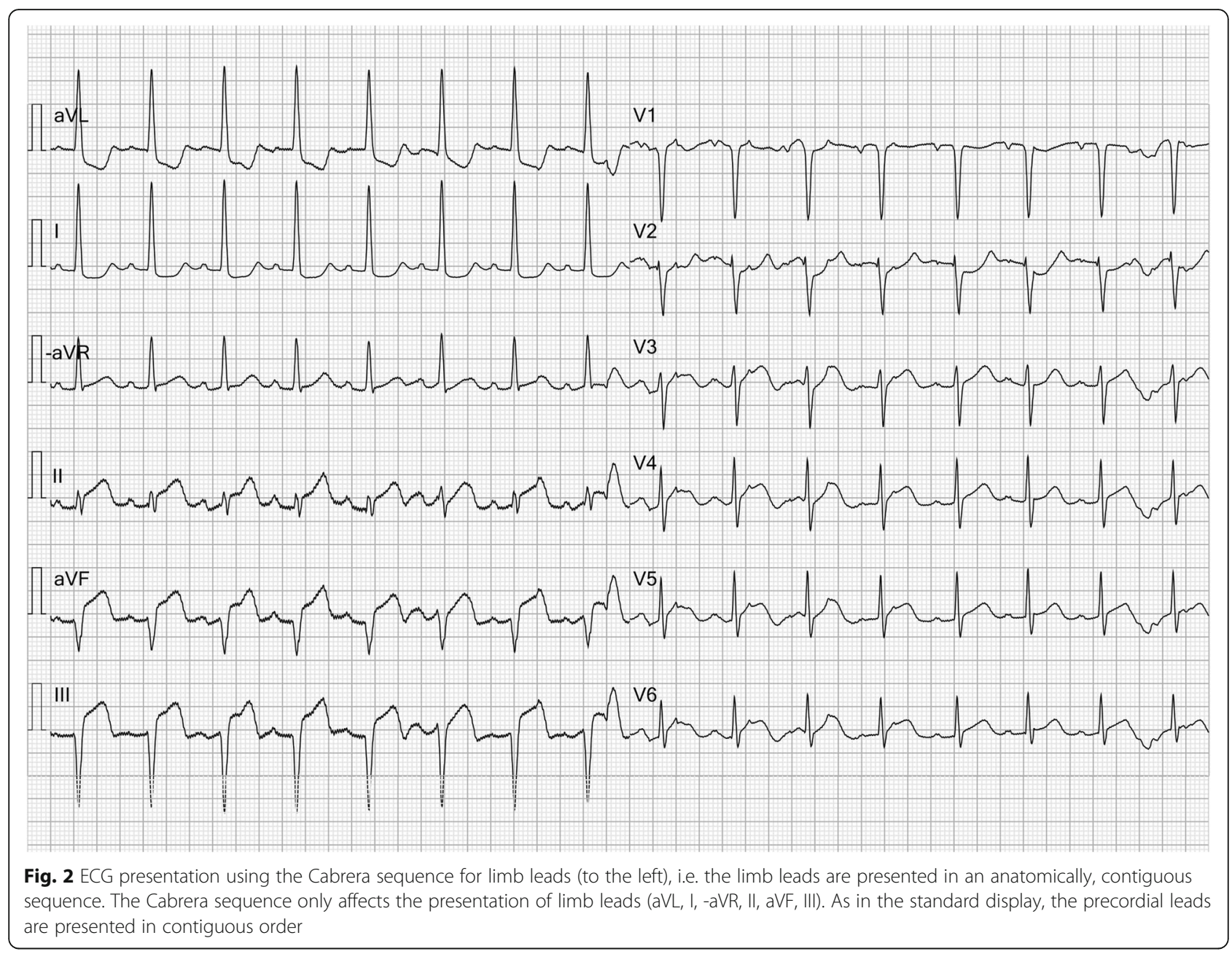

Lead III and - aVL, as well as aVL and - III are "neighboring leads" (Fig. 3b). This is likely well appreciated if the ECG is presented, and taught to medical students, with the leads displayed in contiguous order.

ST changes in aVL carry important information in patients with inferior ST elevation [5, 6]. ST depression in $\mathrm{aVL}$ (i.e. ST elevation in -aVL) in inferior STEMI has been shown to indicate severe disease and poor left ventricular ejection fraction [7], and to increase detection rate in inferior STEMI $[5,8,9]$. ST depression $>0.1 \mathrm{mV}$ in aVL is indicative of right ventricular (RV) infarction [10]. RV involvement in inferior STEMI is associated with increased risk of major complications, such as ventricular arrythmias, cardiogenic shock and death [11]. A recent study showed that differential diagnostic information may be added by assessing aVL in inferior ST elevation when differentiating between STEMI and pericarditis. In 154 STEMI patients, ST depression in aVL (at least $0.025 \mathrm{mV}$ ) was present in all patients, but in none of the patients with pericarditis [9]. Furthermore, ST depression in aVL and larger ST elevation in lead III than in lead II, indicates a right coronary artery (RCA) culprit (Fig. 4, left image) [12]. This can also be illustrated as a more rightward orientation of the ST segment deviation, with significant ST elevation in -aVL.

It is also important to include aVL in the interpretation of anterior ST elevation. When the left anterior descending coronary artery (LAD) is occluded proximal to the first diagonal branch, ST elevation in aVL and I is often present [13]. If LAD is long and "wraps" around the apex, ischemia of the inferior wall will also be present. If ischemia is present in both these areas, the "ischemic currents" of the lateral and inferior regions may oppose one another, reducing the number of leads with ST elevation [13]. This phenomenon is easily understood if one acknowledges that aVL is almost reciprocal to lead III (Fig. 3b).

\section{Neglect of aVR}

Likely due to its different waveform morphology compared to the other limb leads, lead aVR is often ignored during ECG interpretation [14]. When 35 participants at an international scientific meeting on electrocardiography were asked to interpret 5 ECGs, the majority did 


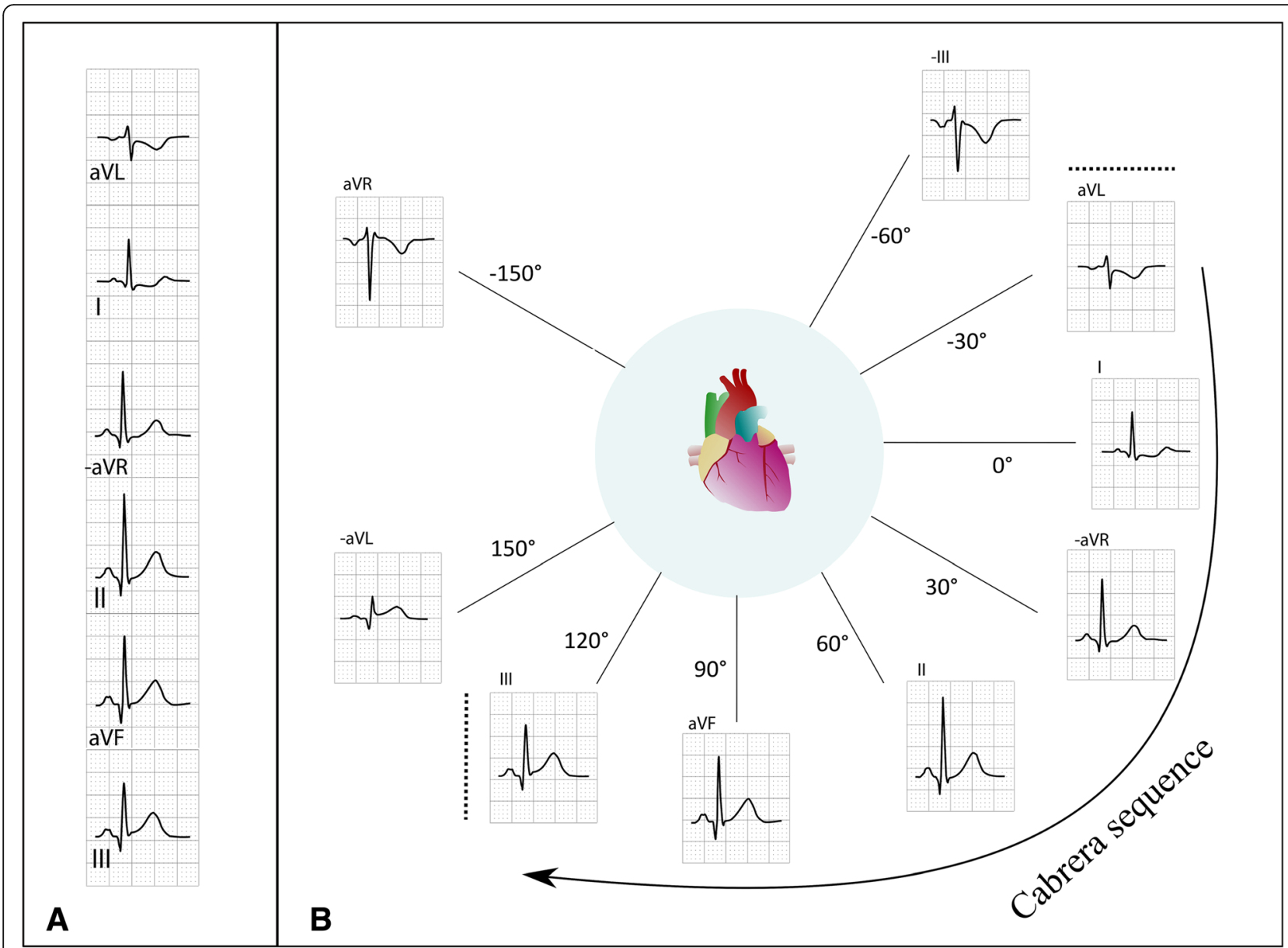

Fig. 3 Panel A shows the Cabrera presentation of leads. The leads are presented in contiguous order. Compared to the standard format, aVR is replaced by $-\mathrm{aVR}$. The relation between the limb leads according to the frontal axis is evident in Panel B. The Cabrera sequence is demarcated by the dashed lines above lead $\mathrm{aVL}$ and to the left of lead III. Lead aVR, which is included in standard display, is completely different from the other leads, with its positive pole in the upper right quadrant of the thorax. In the Cabrera display, the inverted version -aVR instead bridges the gap between lead I and II, resulting in a smooth waveform progression. This ECG, from a patient with RCA occlusion, shows significant ST elevation in only one lead, lead III, but reciprocal ST depression in aVL. Since -aVL is opposite to aVL and next to III, significant ST elevation can be considered to be present in two contiguous leads, III and - aVL

not notice that aVR in all ECGs had been replaced by its inverted version [15]. Following this report, the importance of including aVR in ECG interpretation has been highlighted in several papers [14, 16-22]. ST elevation and positive $T$ waves in aVR have been found to carry independent prognostic information [23, 24]. In patients with NSTEMI, ST elevation in aVR was associated with an increased risk of death, recurrent infarction and heart failure [24]. ST elevation in aVR in combination with ST depression in the precordial leads has been reported as a sign of three-vessel disease or left main coronary artery (LMCA) occlusion (Fig. 4, middle image) [14, 17, 25-30]. The widespread ST depression in combination with ST elevation in aVR seen in patients with left main stenosis reflects "circumferential subendocardial ischemia" [26]. This may also be present also in other conditions with an imbalance of oxygen supply and demand [26] and is therefore not specific for left main stenosis or three-vessel disease [17]. In patients with anterior STEMI, ST elevation in aVR $>0.05 \mathrm{mV}$ can be a sign of proximal LAD occlusion (Fig. 4, right image) [31]. A proximal LAD occlusion site is associated with increased infarct size and increased short and long-term mortality, compared to mid- or distal occlusion sites, even in PCI-treated patients $[32,33]$. In cases with ST elevation in aVR, a Cabrera presentation of the ECG would hence show ST depression in $-\mathrm{aVR}$, with a smooth transition from the ST depression in its neighboring leads, in a way "de-mystifying" the ST elevation in aVR.

In inferior and lateral STEMI, presence of ST elevation in $-\mathrm{aVR}$ was associated with larger infarct size [22]. The left circumflex coronary artery ( $\mathrm{LCx}$ ) perfuses the lateral segments of the left ventricle, but overlap between RCA and LCX is common [34]. If an inferior STEMI is caused 


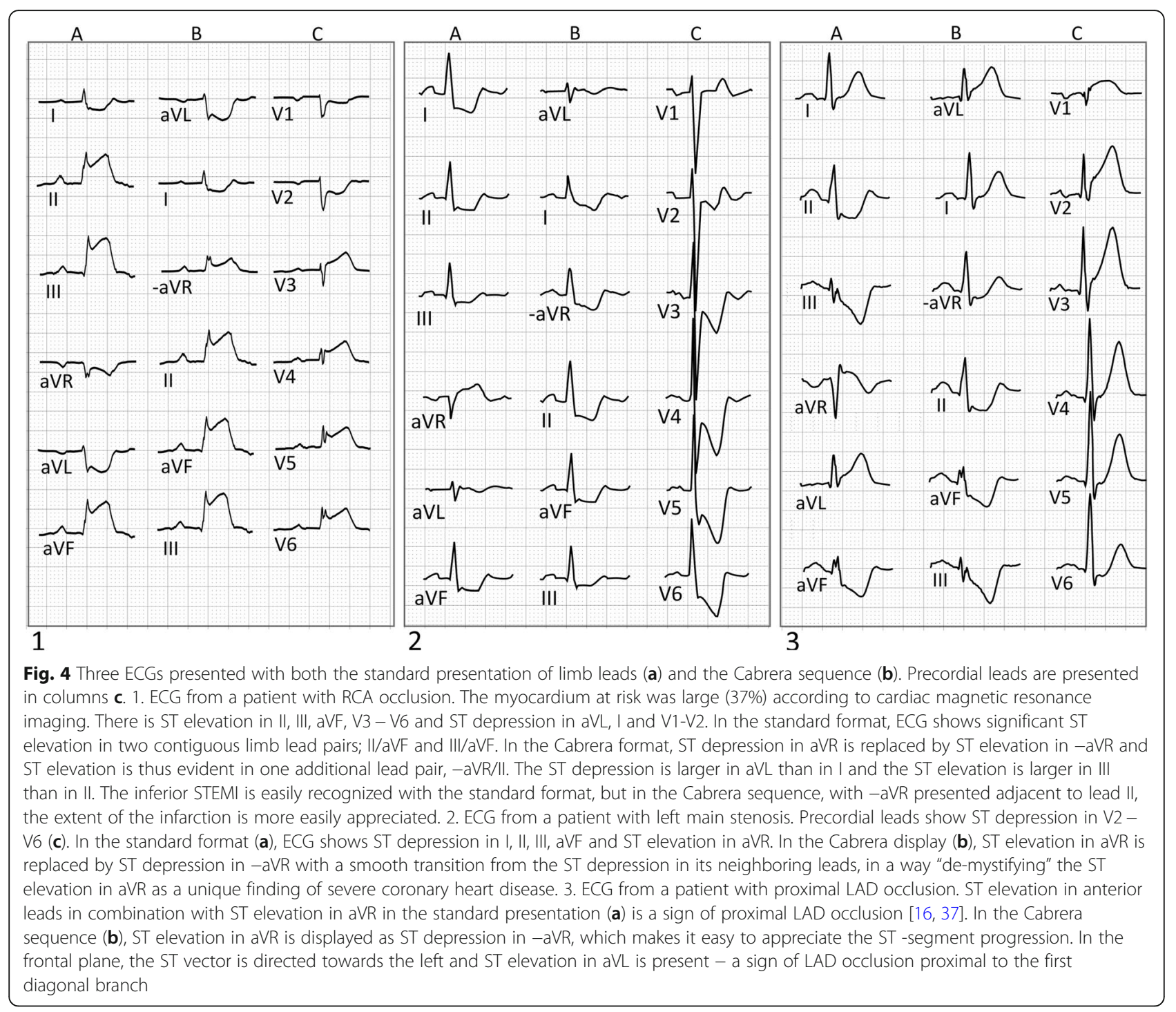

by an LCx occlusion or if the perfusion territory of an occluded RCA is large, ST depression in aVR will be present [35]. This is clearly visualized if leads are presented in contiguous order (Fig. 4, left image).

The use of aVR is considered to be important in the differential diagnosis between STEMI and takotsubo cardiomyopathy [36, 37]. Although ST elevation can be absent on admission ECGs in many cases of takotsubo cardiomyopathy, both the characteristics of the ST elevation, when present, and its time course are similar to those in acute myocardial infarction [36]. Kosuge et al. showed that in patients with ST elevation in the precordial leads, ST depression in aVR was more common in patients with takotsubo cardiomyopathy than in patients with LAD occlusion and suggested that this was more easily recognized by the use of the Cabrera sequence (Fig. 5) [37].
The focus of this debate paper is acute coronary syndrome. However, it deserves to be mentioned that including aVR in ECG interpretation has been described to be important for several other purposes; such as defining the origin of focal atrial tachycardia [38]; differentiating supraventricular [39] and ventricular wide QRS complex arrythmias [40]; and risk stratification of patients with Brugada syndrome [41]. The information in aVR is, of course, not lost by using its inverted version $(-\mathrm{aVR})$, but instead probably less likely to be neglected when it is presented in its logical place between I and II.

As described above, when leads are presented in anatomical order, greater understanding of pathophysiological changes may be obtained. Hurst advised against interpreting ECGs by memorizing patterns and advocated that education in ECG interpretation should focus on understanding the spatial information in the ECG 


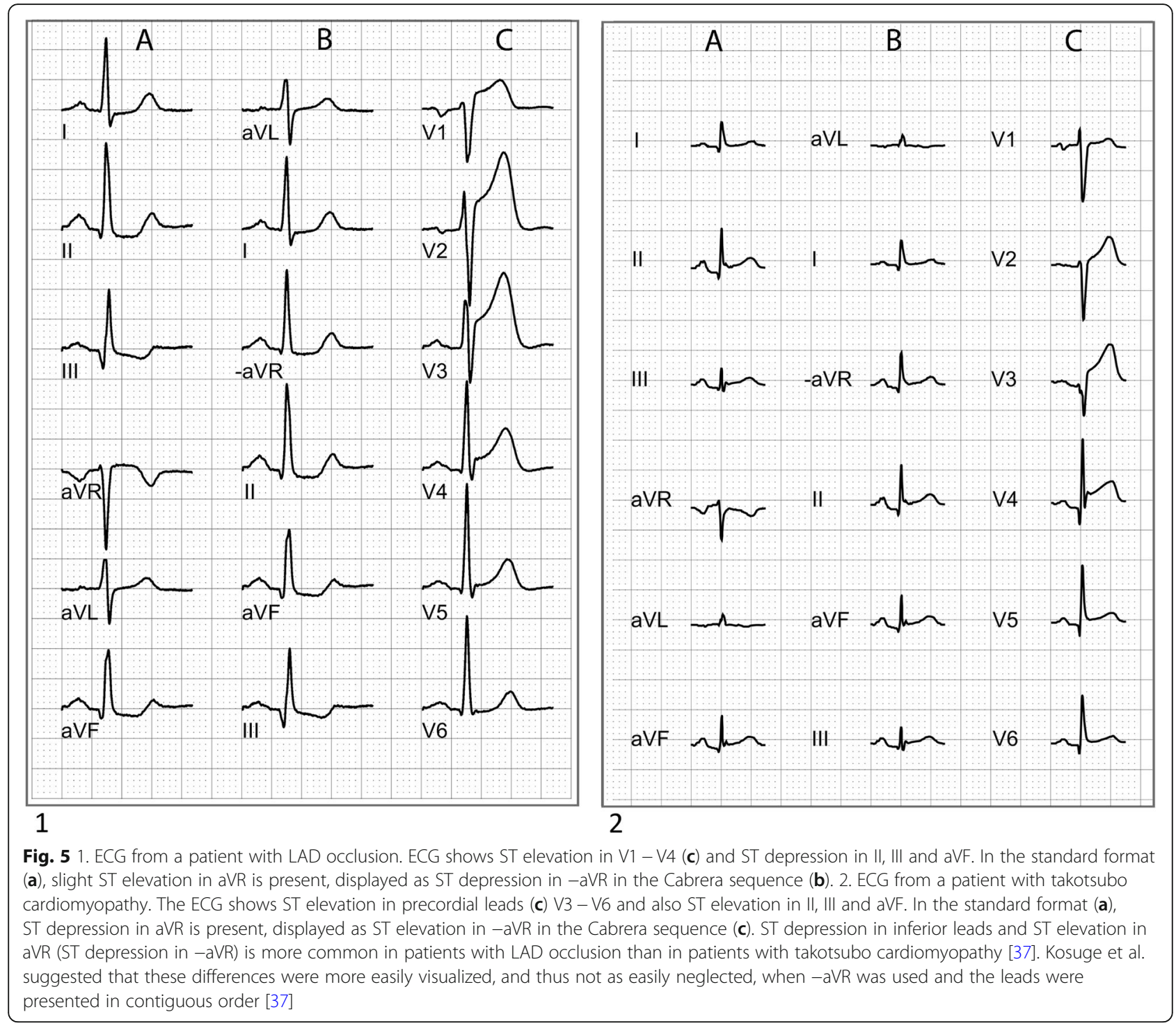

[42]. This is easier when leads are presented in the orderly Cabrera format. A study by Pahlm et al. showed that medical students identified the electrical axis faster and more correctly when using an ECG with the Cabrera display compared to the standard display [43], and the same would likely apply to the ST-segment axis in the frontal plane. Eslava et al. showed poor accuracy in ECG interpretation by internal medicine residents. ECGs representing acute myocardial infarction were the most correctly interpreted, but only $83 \%$ of those ECGs were correctly interpreted [1]. Besides the need of a structured ECG training curriculum [44], it is important that the ECG is displayed as logically and intuitively as possible, especially when ECG training for both students and clinical residents has to compete with other important clinical areas.
After the introduction of the Cabrera display in the 1950's [45] several authors have recommended its use [46-51]. This display has been promoted in a position paper in the Journal of Electrocardiology [52], and was included as an appropriate alternative to the standard display in the recommendations for standardization of the electrocardiogram (2009) endorsed by both the American Heart Association and the American College of Cardiology [53]. It was successfully introduced in Sweden in the 1970's but has gained less interest in other countries though it is used regionally in some countries, e.g. Finland, Japan, and Italy. Tradition and technical difficulties are the most likely reasons for the limited use of the Cabrera display. Nowadays, the technical difficulties are easily overcome since digital ECG software can present any display format as well as inverted leads. 
Although the Cabrera sequence is an intuitive and logical presentation of limb leads, the change of display format would require an effort for many physicians in adapting to a new format, and comparisons of previous ECGs may become difficult unless the ECG software can switch easily between formats. Also, although lead $-\mathrm{aVR}$ has been included in clinical STEMI detection in Sweden for decades, scientific evidence on its use and its implications on decision making regarding reperfusion therapy is still lacking. Future studies on the value of the Cabrera sequence compared to the standard display format are needed and encouraged, especially regarding sensitivity and specificity for the diagnosis of acute coronary syndrome.

\section{Conclusions}

It is logical to display the limb leads in their sequential anatomical order (Fig. 1), and it may have advantages both in diagnostics and ECG learning. Therefore, we encourage future studies on the value of the Cabrera sequence in ECG interpretation and education.

\section{Abbreviations}

$L A D$ : Left anterior descending coronary artery; $L C X$ : Left circumflex coronary artery; LMCA: Left main coronary artery; RCA: Right coronary artery; RV: Right ventricular; STEMI: ST-elevation myocardial infarction; NSTEMI: Non STelevation myocardial infarction

\section{Acknowledgements}

The authors want to thank professor Paul Kligfield for his valuable and constructive critique of our paper.

\section{Funding}

Funding for this project has been received only for publication fees (open access) from the Department of Research and Development, Region Kronoberg, Sweden.

\section{Availability of data and materials \\ Not applicable.}

\section{Authors' contributions}

$T L$ performed the initial draft of the paper with the supervision of OP. All authors analyzed the ECGs included. All authors contributed with critical revisions and important intellectual content during the writing of the manuscript. All authors read and approved the final version of the manuscript.

\section{Ethics approval and consent to participate}

Not applicable.

\section{Consent for publication}

Not applicable.

\section{Competing interests}

The authors declare that they have no competing interests.

\section{Publisher's Note}

Springer Nature remains neutral with regard to jurisdictional claims in published maps and institutional affiliations.

\section{Author details}

${ }^{1}$ Department of Clinical Physiology, Växjö Central Hospital, Växjö, Sweden. ${ }^{2}$ Department of Research and Development, Region Kronoberg, Sweden. ${ }^{3}$ Clinical Sciences, Clinical Physiology, Lund University, Växjö, Sweden. ${ }^{4}$ The Section of Cardiology, Baylor College of Medicine, and the Texas Heart Institute, Baylor St Luke Medical Center, Houston, TX, USA. ${ }^{5}$ Heart Center, Tampere University Hospital, Tampere, Finland. ${ }^{6}$ Faculty of Medicine and Life Sciences, University of Tampere, Tampere, Finland. ${ }^{7}$ Department of Cardiology, Leiden University Medical Center, Leiden, The Netherlands. ${ }^{8}$ Clinical Sciences, Emergency Medicine, Skane University Hospital, Lund, Sweden. ${ }^{9}$ Clinical Physiology and Nuclear Medicine, Skane University Hospital, Lund, Sweden.

Received: 25 October 2018 Accepted: 11 December 2018

Published online: 10 January 2019

\section{References}

1. Eslava D, Dhillon S, Berger J, Homel P, Bergmann S. Interpretation of electrocardiograms by first-year residents: the need for change. J Electrocardiol. 2009;42(6):693-7.

2. Berger JS, Eisen L, Nozad V, D'Angelo J, Calderon Y, Brown DL, et al. Competency in electrocardiogram interpretation among internal medicine and emergency medicine residents. Am J Med. 2005;118(8):873-80.

3. Sodi-Pallares D, Cuellar A, Cabrera E. Sistema de 6 ejes con aplicacion al vector AT en las hipertrofias ventriculares. Arch Inst Cardiol Mexico. 1944;1945(14):142-9.

4. Thygesen K, Alpert JS, Jaffe AS, Simoons ML, Chaitman BR, White HD, et al. Third universal definition of myocardial infarction. Eur Heart J. 2012;33(20):2551-67.

5. Birnbaum Y, Sclarovsky S, Mager A, Strasberg B, Rechavia E. ST segment depression in aVL: a sensitive marker for acute inferior myocardial infarction. Eur Heart J. 1993;14(1):4-7.

6. Hasdai D, Birnbaum Y, Herz I, Sclarovsky S, Mazur A, Solodky A. ST segment depression in lateral limb leads in inferior wall acute myocardial infarction implications regarding the culprit artery and the site of obstruction. Eur Heart J. 1995;16(11):1549-53.

7. Parale GP, Kulkarni PM, Khade SK, Athawale S, Vora A. Importance of reciprocal leads in acute myocardial infarction. J Assoc Physicians India. 2004;52:376-9.

8. Hassen GW, Talebi S, Fernaine G, Kalantari H. Lead aVL on electrocardiogram: emerging as important lead in early diagnosis of myocardial infarction? Am J Emerg Med. 2014;32(7):785-8.

9. Bischof JE, Worrall C, Thompson P, Marti D, Smith SW. ST depression in lead aVL differentiates inferior ST-elevation myocardial infarction from pericarditis. Am J Emerg Med. 2016;34(2):149-54

10. Turhan H, Yilmaz MB, Yetkin E, Atak R, Biyikoglu SF, Senen K, et al. Diagnostic value of aVL derivation for right ventricular involvement in patients with acute inferior myocardial infarction. Ann Noninvasive Electrocardiol. 2003;8(3):185-8.

11. Mehta SR, Eikelboom JW, Natarajan MK, Diaz R, Yi C, Gibbons RJ, et al. Impact of right ventricular involvement on mortality and morbidity in patients with inferior myocardial infarction. J Am Coll Cardiol. 2001;37(1):37-43.

12. Huang $X$, Ramdhany SK, Zhang Y, Yuan ZY, Mintz GS, Guo N. New STsegment algorithms to determine culprit artery location in acute inferior myocardial infarction. Am J Emerg Med. 2016;34(9):1772-8.

13. Atar S, Birnbaum Y. Ischemia-induced ST-segment elevation: classification, prognosis, and therapy. J Electrocardiol. 2005;38(4 Suppl): $1-7$.

14. Riera AR, Ferreira C, Ferreira Filho C, Dubner S, Barbosa Barros R, Femenia F, et al. Clinical value of lead aVR. Ann Noninvasive Electrocardiol. 2011;16(3):295-302

15. Pahlm US, Pahlm O, Wagner GS. The standard 11-lead ECG. Neglect of lead aVR in the classical limb lead display. J Electrocardiol. 1996;(29 Suppl):270-4.

16. George A, Arumugham PS, Figueredo VM. aVR - the forgotten lead. Exp Clin Cardiol. 2010;15(2):e36-44.

17. Knotts RJ, Wilson JM, Kim E, Huang HD, Birnbaum Y. Diffuse ST depression with ST elevation in aVR: is this pattern specific for global ischemia due to left main coronary artery disease? J Electrocardiol. 2013;46(3):240-8. 
18. Gorgels AP, Engelen DJ, Wellens HJ. Lead aVR, a mostly ignored but very valuable lead in clinical electrocardiography. J Am Coll Cardiol. 2001;38(5):1355-6.

19. Kanei $Y$, Sharma J, Diwan R, Sklash R, Vales LL, Fox JT, et al. ST-segment depression in aVR as a predictor of culprit artery and infarct size in acute inferior wall ST-segment elevation myocardial infarction. J Electrocardiol. 2010;43(2):132-5.

20. Kosuge M, Kimura K, Ishikawa T, Ebina T, Hibi K, Toda N, et al. ST-segment depression in lead aVR: a useful predictor of impaired myocardial reperfusion in patients with inferior acute myocardial infarction. Chest. 2005;128(2):780-6.

21. Sun TW, Wang LX, Zhang YZ. The value of ECG lead aVR in the differential diagnosis of acute inferior wall myocardial infarction. Intern Med. 2007:46(12):795-9.

22. Menown IB, Adgey AA. Improving the ECG classification of inferior and lateral myocardial infarction by inversion of lead aVR. Heart. 2000;83(6):657-60

23. Kobayashi A, Misumida N, Aoi S, Kanei Y. Positive T wave in lead aVR as an independent predictor for 1-year major adverse cardiac events in patients with first anterior wall ST-segment elevation myocardial infarction. Ann Noninvasive Electrocardiol. 2017;22(6).

24. Barrabes JA, Figueras J, Moure C, Cortadellas J, Soler-Soler J. Prognostic value of lead aVR in patients with a first non-ST-segment elevation acute myocardial infarction. Circulation. 2003;108(7):814-9.

25. Sen F, Ozeke O, Kirbas O, Burak C, Kafes H, Tekin Tak B, et al. Classical electrocardiographic clues for left main coronary artery disease. Indian Heart J. 2016:68(Suppl 2):S226-s7.

26. Nikus KC, Eskola MJ. Electrocardiogram patterns in acute left main coronary artery occlusion. J Electrocardiol. 2008;41(6):626-9.

27. Yamaji H, Iwasaki K, Kusachi S, Murakami T, Hirami R, Hamamoto H, et al. Prediction of acute left main coronary artery obstruction by 12-lead electrocardiography. ST segment elevation in lead aVR with less ST segment elevation in lead V(1). J Am Coll Cardiol. 2001;38(5):1348-54.

28. Gorgels AP, Vos MA, Mulleneers R, de Zwaan C, Bar FW, Wellens HJ. Value of the electrocardiogram in diagnosing the number of severely narrowed coronary arteries in rest angina pectoris. Am J Cardiol. 1993;72(14):999-1003.

29. Kosuge M, Kimura K, Ishikawa T, Ebina T, Hibi K, Tsukahara K, et al. Combined prognostic utility of ST segment in lead aVR and troponin T on admission in non-ST-segment elevation acute coronary syndromes. Am J Cardiol. 2006;97(3):334-9.

30. Gaitonde RS, Sharma N, Ali-Hasan S, Miller JM, Jayachandran JV, Kalaria VG. Prediction of significant left main coronary artery stenosis by the 12-lead electrocardiogram in patients with rest angina pectoris and the withholding of clopidogrel therapy. Am J Cardiol. 2003;92(7):846-8.

31. Engelen DJ, Gorgels AP, Cheriex EC, De Muinck ED, Ophuis AJ, Dassen WR, et al. Value of the electrocardiogram in localizing the occlusion site in the left anterior descending coronary artery in acute anterior myocardial infarction. J Am Coll Cardiol. 1999;34(2):389-95.

32. Elsman P, van 't Hof AW, Hoorntje JC, de Boer MJ, Borm GF, Suryapranata H, et al. Effect of coronary occlusion site on angiographic and clinical outcome in acute myocardial infarction patients treated with early coronary intervention. Am J Cardiol. 2006;97(8):1137-41.

33. Brener SJ, Witzenbichler B, Maehara A, Dizon J, Fahy M, El-Omar M, et al. Infarct size and mortality in patients with proximal versus mid left anterior descending artery occlusion: the intracoronary Abciximab and aspiration Thrombectomy in patients with large anterior myocardial infarction (INFUSE-AMI) trial. Am Heart J. 2013;166(1):64-70.

34. Nordlund D, Heiberg E, Carlsson M, Fründ E-T, Hoffmann P, Koul S, et al. Extent of myocardium at risk for left anterior descending artery, right coronary artery, and left circumflex artery occlusion depicted by contrastenhanced steady state free precession and T2-weighted short tau inversion recovery magnetic resonance Imaging CLINICAL PERSPECTIVE. Circ Cardiovasc Imaging. 2016;9(7):e004376.

35. Nair R, Glancy DL. ECG discrimination between right and left circumflex coronary arterial occlusion in patients with acute inferior myocardial infarction: value of old criteria and use of lead aVR. Chest. 2002;122(1):134-9.

36. Frangieh AH, Obeid S, Ghadri J-R, Imori Y, D'Ascenzo F, Kovac M, et al. ECG criteria to differentiate between Takotsubo (stress) cardiomyopathy and myocardial infarction. J Am Heart Assoc. 2016;5(6).
37. Kosuge M, Kimura K. Implications of using the Cabrera sequence for diagnosing acute coronary syndrome. Circ J. 2016;80(5):1087-96.

38. Tada H, Nogami A, Naito S, Suguta M, Nakatsugawa M, Horie $Y$, et al. Simple electrocardiographic criteria for identifying the site of origin of focal right atrial tachycardia. Pacing Clin Electrophysiol. 1998;21(11 Pt 2):2431-9.

39. Ho YL, Lin LY, Lin JL, Chen MF, Chen WJ, Lee YT. Usefulness of ST-segment elevation in lead aVR during tachycardia for determining the mechanism of narrow QRS complex tachycardia. Am J Cardiol. 2003;92(12):1424-8.

40. Vereckei A, Duray G, Szenasi G, Altemose GT, Miller JM. New algorithm using only lead aVR for differential diagnosis of wide QRS complex tachycardia. Heart Rhythm. 2008:5(1):89-98.

41. Babai Bigi MA, Aslani A, Shahrzad S. aVR sign as a risk factor for lifethreatening arrhythmic events in patients with Brugada syndrome. Heart Rhythm. 2007;4(8):1009-12.

42. Hurst JW. Methods used to interpret the 12-lead electrocardiogram: pattern memorization versus the use of vector concepts. Clin Cardiol. 2000;23(1):4-13.

43. Pahlm US, O'Brien JE, Pettersson J, Pahlm O, White T, Maynard C, et al. Comparison of teaching the basic electrocardiographic concept of frontal plane QRS axis using the classical versus the orderly electrocardiogram limb lead displays. Am Heart J. 1997;134(6):1014-8.

44. Antiperovitch P, Zareba W, Steinberg JS, Bacharova L, Tereshchenko LG, Farre J, et al. Proposed in-training electrocardiogram interpretation competencies for undergraduate and postgraduate trainees. J Hosp Med. 2018:13(3):185-93.

45. Graettinger JS, Packard JM, Graybiel A. A new method of equating and presenting bipolar and unipolar extremity leads of the electrocardiogram; advantages gained in visualization of their common relationship to the electric field of the heart. Am J Med. 1951;11(1):3-25.

46. Dower GE, Nazzal SB, Pahlm O, Haistey WK Jr, Marriott HL, Bullington RH, et al. Limb leads of the electrocardiogram: sequencing revisited. Clin Cardiol. 1990;13(5):346-8.

47. Case RB, Tansey WA, Mogtader AH. A sequential angular lead presentation. J Electrocardiol. 1979;12(4):395-401.

48. Fumagalli B. Unipolar value of standard limb leads; lead -VR and rational arrangement of limn leads. Am Heart J. 1954;48(2):204-23.

49. Case RB, Moss AJ. Recommendation for revision of the standard presentation of the frontal plane ECG leads including reversal of lead aVR (to -aVR): it is time for a change. Ann Noninvasive Electrocardiol. 2010;15(2):97-100

50. Sgarbossa EB, Barold SS, Pinski SL, Wagner GS, Pahlm O. Twelve-lead electrocardiogram: The advantages of an orderly frontal lead display including lead -aVR. J Electrocardiol. 2004;37(3):141-7.

51. Lam A, Wagner GS, Pahlm O. The classical versus the Cabrera presentation system for resting electrocardiography: impact on recognition and understanding of clinically important electrocardiographic changes. J Electrocardiol. 2015;48(4):476-82.

52. Anderson ST, Pahlm O, Selvester RH, Bailey JJ, Berson AS, Barold SS, et al. Panoramic display of the orderly sequenced 12-lead ECG. J Electrocardiol. 1994;27(4):347-52

53. Wagner GS, Macfarlane P, Wellens H, Josephson M, Gorgels A, Mirvis DM, et al. AHA/ACCF/HRS recommendations for the standardization and interpretation of the electrocardiogram: part Vl: acute ischemia/infarction: a scientific statement from the American Heart Association electrocardiography and arrhythmias committee, council on clinical cardiology; the American College of Cardiology Foundation; and the Heart Rhythm Society. Endorsed by the International Society for Computerized Electrocardiology. J Am Coll Cardiol. 2009:53(11):1003-11. 